\title{
Evaluation of Parents' Awareness and Knowledge about Problems and Issues Related to Their Premature Infants in an Iranian Hospital
}

\author{
Nasrin Khalesi1,2, Fatemeh Shoaae Anjom¹, Golnaz Rezaeiezadeh ${ }^{3}$, Zahra Farahani ${ }^{2 *}$ \\ ${ }^{1}$ Neonatal Division, Aliasghar Hospital, Iran University of Medical Sciences, Tehran, Iran \\ ${ }^{2}$ Maternal, Fetal \& Neonatal Research Center, Tehran University of Medical Sciences, Tehran, Iran \\ ${ }^{3}$ Breastfeeding Research Center, Tehran University of Medical Sciences, Tehran, Iran \\ Email: nasrinkhalessi@yahoo.com, mfnhrc@tums.ac.ir, golnaz_rezaei80@yahoo.com, \\ fetuspapyrus@gmail.com
}

Received 1 April 2015; accepted 10 May 2015; published 13 May 2015

Copyright (C) 2015 by authors and Scientific Research Publishing Inc.

This work is licensed under the Creative Commons Attribution International License (CC BY).

http://creativecommons.org/licenses/by/4.0/

(c) (i) Open Access

\begin{abstract}
Premature infant is an infant who was born before the end of 37th weeks of pregnancy. Approximately $9.6 \%$ of infants are premature and they can be at risk for hospitalization. This study has done for evaluation of awareness and knowledge of parents about problems of premature infants in Neonatal Intensive Care Unit (NICU). This was a descriptive study with 160 parents whose premature infants were admitted to NICU (Tehran-Iran, 2009-2011). Data were collected by a questionnaire for evaluation of awareness and knowledge of parents about problems of prematurity, and then analyzed by using descriptive analytic statistical methods and SPSS software. Based on the results, there was a significant relation between age and the total score of questionnaire $(P=$ $0.022, R=0.18)$. Mothers had higher awareness and knowledge than fathers $(P<0.05)$. The most awareness in parents was about doing of hygienic principle when they entered to NICU and about the importance of regularly and continuous attendance in ward. Awareness and knowledge of parents about problems of their premature infant were related to their age and being a mother or father. Parents had little knowledge about some NICU principles and premature infant's needs and care.
\end{abstract}

\section{Keywords}

Awareness, Knowledge, Infant, Neonatal Intensive Care Unit, Prematurity

\footnotetext{
${ }^{*}$ Corresponding author.
}

How to cite this paper: Khalesi, N., Anjom, F.S., Rezaeiezadeh, G. and Farahani, Z. (2015) Evaluation of Parents' Awareness and Knowledge about Problems and Issues Related to Their Premature Infants in an Iranian Hospital. Open Journal of Nursing, 5, 465-469. http://dx.doi.org/10.4236/ojn.2015.55049 


\section{Introduction}

Premature infant is an infant who was born before the end of 37th week of pregnancy. Due to some complications associated prematurity, these infants need to hospitalize in Neonatal Intensive Care Unit (NICU) [1]. In recent years, factors such as assisted reproductive technology, old age pregnancy, advanced ante/postnatal diagnosis and treatments cause a rise in preterm birth rate [2]. The rate of preterm birth in 2005 was reported 12.9 million births (9.6\%) worldwide and about 11 million (85\%) in Africa and Asia [3].

The births of a premature and critically sick infant make parents experience a very stressful situation [4]. These stress and tension may relate to lack of awareness and knowledge in care and interaction with premature infants [5]. It seems that women in reproductive age do not have enough general knowledge about prematurity and associated problems, so educational intervention in NICU is necessary [6].

Parents in NICU have a great and active role in care giving process like feeding, bathing, and physical care in which this relation and interaction have a positive effect on mother and infant emotionally and physically. Health professional and staff help parents to know more about their ill children's condition by sharing their knowledge and experience [7]. Parents' participation in care process, providing information, communication with health professional, and decision making affect on infant development and early discharge from NICU [8][10].

Assessments of parental knowledge, experience and teaching process during hospitalization days surely improve NICU service and outcome of prematurity. This quantitative study has done for evaluation of awareness and knowledge of parents about problems of their premature infants who have hospitalized in NICU. In this study we also assess the role of parents' sex, age, parity, education on their knowledge.

\section{Materials and Methods}

A descriptive cross-sectional study was carried out in the NICU of Ali-Asghar, a tertiary referral center and also one of the teaching hospitals affiliated to Iran University of Medical Sciences between 2009 and 2011.Target population was 160 parents. The criterion for inclusion was being parent (father or mother) of hospitalized premature infant (gestational age $<37$ weeks) for at least 24 hours. We recorded some demographic data such as parents' age, sex, parity and education. Then we asked parents to fill out a questionnaire contained 20 questions about premature infant's needs and care. This questionnaire was prepared based on literature text of neonatology (Fanaroff), Text of pediatric (Nelson), Manual of neonatal care (Cloherty). Questionnaire was evaluated by experts. The validity and reliability was evaluated and the scale was reliable for this sample $(\alpha=0.80)$.

In each question, we explained a prematurity related complication and its necessary care process. Then parents were asked whether know these information or not. Parents should respond by choosing one of 2 options for each; I know or I do not know.

In the research questionnaire we used some questions to identify parents' knowledge about; the importance of parents attendance in ward, threatening condition like intra ventricular hemorrhage, hearing loss, eye problems and rickets in premature infants, breastfeeding route, fortifier adding (dose) and supplemental need, markers of neonates weight gain, routine pediatrician and other specialists visits, para clinical follow ups (brain and hip joint sonography, OAE, ABR, ...), vaccination and its timetable, and finally knowledge about room and baby temperature. Score 4 was allocated for each positive and 2 for each negative answer. We analyzed recorded data by SPSS software; frequency by mean \pm SD, quantitative variables correlation with Student T test, Pearson correlation coefficient and qualitative variables with Chi Square when they were applicable.

The study was approved by the Medical Ethics Committee according Helsinki declaration. All participants gave informed consent before entering the study. Our gathered data were confidential and no extra cost was constrained on our participants.

\section{Results}

Among 160 parents with mean age $27.1 \pm 5.1$ years, 139 participants (86.9\%) were female. Of all parents; $56.9 \%$ had one child and the rest had 2 - 4. Eighty people were under graduate and 80 cases had bachelor or higher degree. Background data was shown in Table 1.

Majority of parents had positive answer about the importance of regularly parents' attendance in ward, avoiding of baby kissing, neonates presence in crowded places and washing hand for 2 minutes before ward entrance 
Table 1. Background data of participants.

\begin{tabular}{cc}
\hline Variables & Number (160) \\
\hline$\frac{\text { Female }}{\text { male }}[\mathrm{N}(\%)]$ & $\frac{139(86.9)}{21(13.1)}$ \\
Education [N (\%)] & \\
Diploma \& lower & $80(50)$ \\
Higher & $80(50)$ \\
Parity [N (\%)] & \\
1 & $91(56.9)$ \\
2 & $48(30)$ \\
3 & $19(11.9)$ \\
4 & $2(1.2)$ \\
\hline
\end{tabular}

(>80\%). On the other hand, many participants did not have enough information about post discharge care, para clinical follow up, specialist visits, and Etc. Table 2 shows the rate of parents' awareness about premature neonates' care processes.

Based on our result mean score for 160 participants was $58.8 \pm 7.1$. By the Pearson correlation coefficient we saw a significant correlation between age and total score ( $\mathrm{P}$ value $=0.022, \mathrm{R}=0.181$ ), in addition Using Chi Square test, mothers' awareness and knowledge were significantly higher than fathers' $(\mathrm{P}<0.05)$.

\section{Discussion}

Prematurity is the main cause of neonatal mortality rate worldwide. Parents of children admitted in NICU need lots of information to engage in the treatment process and supportive care. Health care professionals in NICU, printed materials, audio recording of neonatologist consultation consider useful and worthy information source [4]. If parents omitted from care and decision making process, they would stop feeling responsibility [8].

Reported studies during 1970s to 90s have shown that invasive and aggressive cares ventilation machine and tubes, long mother-infant separation result high tension in parents. Parents desire to discharge their babies sooner however they feel stress due to lack of experience, knowledge and ability to provide necessary care [11].

In a study; Shieh et al. in 2010 compared two group mothers with and without training course before infant NICU discharge. After 3 months level of knowledge providing infant care and mothers' self confidence were higher in parents undergoing education [12].

The recent study showed that among 20 questions, the most parents' awareness belongs to 3 questions; first, continuous attendance in ward. Ninety percepts' of parents had this information that presence in NICU is important. The American Association of Pediatrics recommended that parents attendance result valuable benefits such as decreasing parents' stress, improving the infant clinical recovery and relief the infant's pain [9].

Second; the vast majority of parents knew that they should wash their hand and obey hygienic principle before NICU entrance. Hand contamination is an important source of infection in NICU. Several Studies confirmed an inverse correlation between infection rates and hand Hygiene compliance rates [13]. The high sensibility of NICU staff may useful to persuade parents to observe these principles in NICU.

Third; they also were vigilant about some post discharge care such as avoiding of kissing, trip and presence in crowded places which all of them increase the risk of respiratory and acquired diseases.

On the other hand, the majority of participants did not have enough information about post discharge care, para clinical follow up, and specialist visits. It may relate to impairment in educational system and no accessible information resource for parents after discharge. Parents need some knowledge and skills about basic care feeding, growth, bathing, sleeping, complications such as colic, apnea, noisy birthing. Physicians and nurses are the main sources of information. Teaching and training courses during admission days about post discharge care would be a great help for parents [4]. Lindberg in 2009 reported that parents were satisfied with a videoconference program as a link between NICU and home after home coming with infants. In fact parents experienced and profited the support of hospital staff in new situation at home with preterm babies [14].

In our study few parents knew about timing of immunization in premature infants or process of ventilator support. Our finding was consistent to another study by Robinson et al. [8]. 
Table 2. The rate of parents' awareness about premature neonates’ care processes.

Parent's awareness about subjects

Importance of regularly parents' attendance in ward

Breast feeding (in bottle or NG tube)

Washing hand about 2 minutes before ward entrance

Time of polio vaccination

Normal axillary body temperature $\left(36^{\circ} \mathrm{C}-36.5^{\circ} \mathrm{C}\right)$

Room temperature $\left(25^{\circ} \mathrm{C}-6^{\circ} \mathrm{C}\right)$

Baby feeding interval (each 2 - 3 hours)

Diaper exchange (3 - 6 times/day) as a weight gain criteria

Weekly routine pediatrician visits

Ophthalmologist or retina specialist visit (in 4 - 6 weeks)

Serial brain ultra sonography

Hip joint sonography (in 2 moths)

ENT specialist visit

Specialists consultation for rule out mental, developmental and cognitive diseases

Giving supplements (Fe, Folic acid, Vitamin E)

Avoidance of baby kissing, being in crowded places and long trips in first days post baby discharge

About Vitamin D in preventing of rickets and osteomalcia

One extra hepatitis vaccine in fist month of life (neonates with birth weight < 2000 g)

Dose of fortifier (1 gram in 25 - 50 cc of breast milk)

Influenza vaccination for premature neonates
Positive answer (\%)

89.4

76.2

93.1

68.1

51.9

30

70.6

21.2

19.4

64.4

43.8

14.4

23.1

10

40

96.2

25.6

65.6

18.8

20

We also found a significant correlation between parents' age with knowledge score ( $\mathrm{P}=0.022, \mathrm{R}=0.181$ ). We speculated that older parents had much more experience and knowledge that help them in care of premature infant in NICU.

Based on our result the level of awareness of mothers was higher than fathers. Mothers experience more tension than fathers when premature infant is born [15]. Mothers feel more responsibility about premature baby whereas fathers prefer to leave this duty to hospital staff. Fathers as bread winners usually involve in financial support [16]. A report indicated that mothers in this situation try to empower themselves with health professionals and staff's knowledge and guidance, other mothers or other family members' information [7].

A limitation in our study was the fewer number of fathers that may affect in our results. Mothers and fathers have different perceptions and anticipation. The other limitation may relate that our study was cross-sectional not longitudinal.

Finally, we suggest that future research should focus on different ways to improve parents' knowledge and skills in care of premature newborns.

\section{Conclusion}

The finding of our study provides information that parents need training and educational program to improve their knowledge and skills in care of premature babies. We saw mothers had higher awareness and knowledge than fathers. Older parents had much more knowledge about premature baby complications. The most awareness in parents was about regularly and continuous attendance in ward and doing of hygiene principle when they entered to NICU and some few cares after returning home with premature babies. 


\section{Conflict of Interest}

The authors had no potential conflicts of interest during study.

\section{References}

[1] Riper, M.V. (2001) Family Provider Relationship and Wellbeing in Families with Preterm Infants in the NICU. Heart \& Lung, 30, 74-84. http://dx.doi.org/10.1067/mhl.2001.110625

[2] Arockasamy, V. and Albersheim, S. (2008) Fathers’ Experience in the NICU: A Research for Control. Pediatrics, 121, 215-221.

[3] Beck, S., Wojdyla, D., Say, L., Betran, A.P., Merialdi, M., Requejo, J.H., Rubens, C., Menon, R. and Van Look, P.F. (2010) The Worldwide Incidence of Preterm Birth: A Systematic Review of Maternal Mortality and Morbidity. Bulletin of the World Health Organization, 88, 31-38. http://dx.doi.org/10.2471/BLT.08.062554

[4] Rouck, S.D. and Leys, M. (2009) Information Needs of Parents of Children Admitted to a NICU; a Review of the Literature (1990-2008). Patient Education Counseling, 76, 159-173. http://dx.doi.org/10.1016/j.pec.2009.01.014

[5] Borimnejad, L., Mehrnoush, N. and Seyyed Fatemi, N. (2011) Maternal Stressor Agents with Premature Infantsin NICU. Iranian Journal of Critical Care Nursing, 4, 39-44.

[6] Ling, Z.J., Lian, W.B. and Ho, S.K. (2009) Parental Knowledge of Prematurity and Related Issue. Singapore Medical Journal, 50, 270.

[7] Aagaard, H. and Hall, E. (2008) Mothers' Experience of Having a Preterm Infant in the Neonatal Care Unit: A MetaSynthesis. Journal of Neonatal Nursing, 23, 26-36. http://dx.doi.org/10.1016/j.pedn.2007.02.003

[8] Rabinson, T.M. and Freeman, S.B. (2000) Communication Patterns and Decision Making among Parents and Health Care Providers in the Neonatal Intensive Care Units: A Case Study. Heart \& Lung, 29, 143-148. http://dx.doi.org/10.1067/mhl.2000.105760

[9] Maetinez, J.G., Hemandez, J.R. and Scochi, C.G. (2013) The Hospitalized Preterm Newborn: The Significance of Parents' Participation in the Neonatal Unit. Revista Latino-Americana de Enfermagem, 21, 13060-13066.

[10] Jones, L., Woodhouse, D. and Rowe, R. (2007) Effective Nurse Parent Communication: A Study of Parents' Perception in the NICU Environment. Patient Education and Counseling, 69, 206-212. http://dx.doi.org/10.1016/j.pec.2007.08.014

[11] Miles, M.S., Carlson, J.M.S. and Brunssen, S. (1999) The Nurse Parent Support Tool. Journal of Pediatric Nursing, 14, 44-50. http://dx.doi.org/10.1016/S0882-5963(99)80059-1

[12] Shieh, S.J., Chen, H.L., Liu, F.C., et al. (2010) The Effectiveness of Structured Discharge Education on Maternal Confidence, Caring Knowledge and Growth of Premature Newborns. Journal of Clinical Nursing, 19, 3307-3314. http://dx.doi.org/10.1111/j.1365-2702.2010.03382.x

[13] Mukerji, A., Narciso, J., Moore, C., McGeer, A., Kelly, E. and Shah, V. (2013) An Observational Study of the Hand Hygiene Initiative: A Comparison of Preintervention and Postintervention Outcomes. BMJ Open, 3, 1-7. http://dx.doi.org/10.1136/bmjopen-2013-003018

[14] Lindberg, B., Axelsson, K. and Ohrling, K. (2009) Taking Care of Their Baby at Home but with Nursing Staff as Support: The Use of Videoconference in Providing Neonatal Support to Parents of Preterm Infants. Journal of Neonatal Nursing, 15, 47-55. http://dx.doi.org/10.1016/j.jnn.2009.01.004

[15] D’Souza, S.R.B., Karkada, S., Lewis, L.E., Mayya, S. and Guddattu, V. (2009) Relationship between Stress, Coping and Nursing Support of Parents of Preterm Infants Admitted to Tertiary Level Neonatal Units of Karnataka, India: A Cross-Sectional Survey. Journal of Neonatal Nursing, 15, 152-158. http://dx.doi.org/10.1016/j.jnn.2009.07.003

[16] Ahh, Y.M. and Kim, N.H. (2007) Parental Perception of Neonates, Parental Stress and Education for NICU Parents. Asian Nursing Research, 1, 199-210. http://dx.doi.org/10.1016/S1976-1317(08)60022-5 